\title{
CENTRAL MUSCLE RELAXANT EFFECTS OF DIAZEPAM*
}

\author{
R. D. HudSON and Mary K. Wolpert $\dagger$ \\ Section of Neuroscience, Division of Biological and Medical Sciences, Brown University, Providence, \\ Rhode Island and \\ Department of Pharmacology, The University of Michigan, Ann Arbor, Michigan
}

(Accepted 27 March 1970)

\begin{abstract}
Summary-Motor depressant effects of diazepam were studied in the intact, decerebrate and high spinal cat. Diazepam (0.125-16 $\mathrm{mg} / \mathrm{kg}$, i.v.) produced a depression of both the patellar and linguomandibular reflexes in the intact cat. In the high spinal (C1) cat only the linguomandibular reflex was depressed. Facilitation and inhibition of the patellar reflex elicited in both intact and high spinal (C1) cats were reduced by diazepam. No depression was observed in the in vivo neuromuscular preparation of the tibialis anticus muscle. Small doses of diazepam $(0 \cdot 125 \mathrm{mg} / \mathrm{kg}$, i.v. $)$ abolished the rigidity of the mid-collicular decerebrate cat.

Mean arterial blood pressure was initially depressed in all animals $(0 \cdot 125-2 \mathrm{mg} / \mathrm{kg})$ with an intact medullary vasomotor outflow. Larger doses $(4-16 \mathrm{mg} / \mathrm{kg}$ ) tended to return the blood pressure toward control levels.

The present study presents evidence for both a brain stem reticular and a spinal cord site of action of diazepam on motor systems. Possible mechanisms of action of diazepam on motor systems are discussed.
\end{abstract}

DiazePAM, a 1,4-benzodiazepine derivative, has been clinically and experimentally demonstrated to possess skeletal muscle relaxant properties (Randall et al., 1961; Schallek et al., 1964; SVENSON and GoRDON, 1965).

HERNÁNDEZ-PEÓN et al. (1964) suggested that diazepam may selectively depress reticular facilitatory neurons involved in regulation of postural tone. Evidence for such a brain stem site of action of diazepam was demonstrated by NGal et al. (1966) and Przybyla and Wang (1968).

OLAFSON et al. (1964) postulated that diazepam might have a specific spinal cord site and mechanism of action due to its potency in the treatment of the rare "stiffman" syndrome. This syndrome was theorized to be due to a pathophysiologic block of the spinal synaptic junction between interneurons of the inhibitory pathways and the motoneuron.

The purpose of the present investigation is to further elucidate the central effects of diazepam on motor function in the experimental cat.

\section{METHODS}

Fifty adult cats of both sexes, ranging from 2.5 to $4.6 \mathrm{~kg}$ were used in this investigation. Intact, mid-collicular decerebrate and high spinal $(\mathrm{Cl})$ preparations were utilized.

\footnotetext{
*Supported by Grant MH 13525, USPHS.

A preliminary paper was presented at the Federation Meetings in Atlantic City (HUDson and WOLPERT, 1968).

The diazepant used in this st udy was kindly provided by the Hoffman-La Roche, Inc. Laboratories as Valium. †Present Address: Mary K. Wolpert, Department of Pharmacology, Yale University, New Haven, Connecticut.
} 
Intact

Intact cats anesthetized with sodium pentobarbitone $(30 \mathrm{mg} / \mathrm{kg}, \mathrm{i} . \mathrm{p}$.) or diethyl ether followed by alpha-chloralose (60 mg/kg, i.v.) were suspended in a Horsley-Clarke stereotaxic apparatus by clamping the previously isolated spinous process of the vertebra in the region of the 5 th thoracic and one of the crest of the sacrum. Special clamps were provided for this purpose. These cats were prepared for recording the left patellar reflex, increment and decrement of the patellar reflex in response to stimulation of the reticular formation, linguomandibular reflex, arterial blood pressure, and electroencephalogram of motor cortex.

Arterial blood pressure was recorded at the carotid artery using the Statham P23A pressure transducer. Mean arterial blood pressure was calculated for statistical and graphing purposes.

The patellar reflex was elicited once per second by a mechanically operated hammer. The test limb (left hind) was anchored by a bolt inserted in the femur. The cat's head was stereotaxically fixed and bipolar concentric stimulating electrodes were acutely implanted in the mesencephalic facilitatory (BF) and medullary inhibitory (BI) reticular formation. (For details see HudSON and DomINo, 1963). Stimulation of these sites for a period of $5 \mathrm{sec}$ at a frequency of $100 \mathrm{c} / \mathrm{s}$ with a pulse duration of $1 \mathrm{msec}$ produced patellar reflex increment and decrement respectively. The stimulation voltage ranged from $0 \cdot 3-3 \cdot 2 \mathrm{~V}$. Reflex increment and decrement following cumulative drug doses were compared to control reflex increment and decrement. The standard deviation and standard error of the mean were calculated using the paired comparison Student $t$-test.

The linguomandibular reflex was elicited once every $5 \mathrm{sec}$ by an electric shock applied to the tongue. The linguomandibular monitoring transducer was adjusted in a manner which allowed recording of upward and downward deflections with respect to the baseline.

Following brain stem stimulation the linguomandibular reflex returned to and remained at the control baseline without further deviation (Fig. 2).

The electroencephalogram (EEG) was recorded bipolarly between the cerebral hemispheres in the motor cortical area.

In vivo neuromuscular contractions of the tibialis anticus muscle were obtained in response to electrical stimulation of the severed distal portion of the peroneal nerve.

\section{Decerebrate}

Cats were decerebrated under ether anesthesia. The common carotid arteries were isolated and ligated before brain stem transection to minimize blood loss. A blunt spatula was passed between the inferior and superior colliculi to emerge at the rostral border of the pons. A Gomco vacuum pump (Model No. 792) was used to aspirate a small channel at the posterior aspect of the superior colliculi. A cotton pledget was placed between the cut surfaces.

Decerebrate cats were suspended in the above described apparatus for recording the left patellar reflex and electromyographic (EMG) discharges of the neck muscle. A force displacement transducer, equipped with a special support for the forelimb, was used to register the force exerted by the maintained extensor tonus of the left forelimb. Displacement was calibrated in grams. This parameter was designated as forelimb tone (FT). A decrease in forelimb extensor tone was represented by a fall in the baseline (Fig. 3, panel A). Patellar reflex facilitation and reduction of forelimb tone were produced by stimulation of the ipsilateral pinna.

Carotid artery blood pressure was recorded as in the intact animal. 


\section{Spinal}

The patellar and linguomandibular reflexes and arterial blood pressure were recorded in the anesthetized (sodium pentobarbitone; alpha-chloralose) and unanesthetized (i.e. recovered from ether), vagotomized, high spinal (Cl) cat. Vagi were sectioned to prevent any influence of vagally induced visceral activity. The vertebral arteries were intact and therefore medullary centers were functional. Hence, without vagal section, spurious supraspinal nervous influences could conceivably alter the reflexes recorded. Facilitation and inhibition of the patellar reflex were produced either by high frequency $(120 \mathrm{c} / \mathrm{s})$ stimulation of the contralateral and ipsilateral sciatic nerves respectively or by direct high frequency $(100 \mathrm{c} / \mathrm{s})$ stimulation of the lateral and ventral funiculi of cervical cord segments 1 and 2 (Hudson, 1966).

Diazepam was administered on an accumulative dose schedule at $10 \mathrm{~min}$ intervals via a silastic catheter which was introduced into the right jugular vein and passed down to the level of the right atrium. Drug dose was calculated on the basis of body weight $(0 \cdot 125-$ $16 \mathrm{mg} / \mathrm{kg}$ ). " $P$ " values were determined by the paired and group comparison Student $t$-tests.

In all decerebrate and spinal preparations where ether was used as an anesthetic, unless otherwise indicated, a period of $3 \mathrm{hr}$ was allowed for recovery from the effects of ether before commencing the experiment.

The Beckman type S-II dynograph and the Grass model 5 polygraph recorders were used in this study.

\section{RESULTS}

Effects of diazepam on motor reflexes in the intact anesthetized cat

Figure 1 illustrates the diazepam-produced depression of the patellar reflex $(0.125 \mathrm{mg} / \mathrm{kg}$ $-P>0.02)$, and mean arterial blood pressure $(0.25 \mathrm{mg} / \mathrm{kg}-P>0.05)$. This reduction in

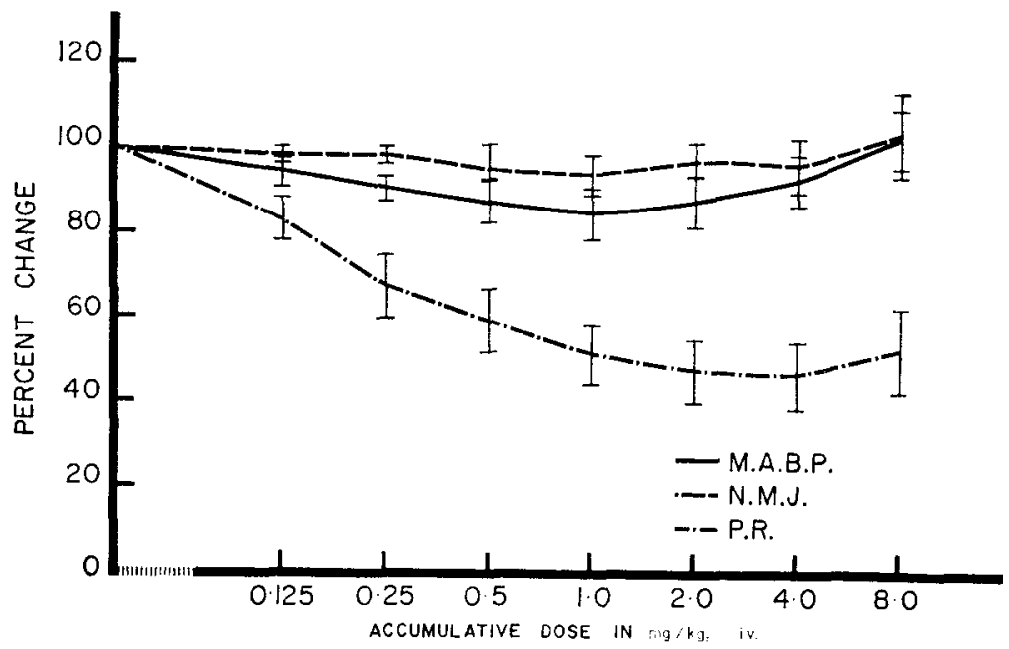

Fig. 1. Effects of diazepam on mean arterial blood pressure (M.A.B.P.), patellar reflex (P.R.) and neuromuscular junction (N.M.J.) in intact cats anesthetized with alpha-chloralose. The mean heights of the patellar reflex and the neuromuscular excursions are expressed as the percentage change from control. The mean arterial blood pressure also is expresscd as pcrecnt change. Accumulative doses of diazepam are plotted logarithmically. The control period was $15 \mathrm{~min}$ and the interval between doses of diazepam was $10 \mathrm{~min}$. The data summarize the results obtained

from 15 animals. The short vertical bars represent \pm standard error of the mean. 
blood pressure continued to the cumulative dose $1-2 \mathrm{mg} / \mathrm{kg}$ where it began to return toward control. At $16 \mathrm{mg} / \mathrm{kg}$ the blood pressure of ten rose above control levels. The neuromuscular preparation was not affected by diazepam (Fig. 1). Figure 2 (panels B-F) shows the diazepaminduced depression of the linguomandibular reflex amplitude $(1 \mathrm{mg} / \mathrm{kg}-P>0.02)$.

\section{Effects of diazepam on brain stem reticular evoked inhibition and facilitation of the patellar reflex.}

Figure 2 (panel B) illustrates the effectiveness of $1.0 \mathrm{mg} / \mathrm{kg}$ of diazepam in depressing patellar reflex increment and decrement $(P<0.02)$ produced by electrical stimulation of mesencephalic facilitatory (BF) and medullary inhibitory (BI) reticular formation. The smallest dose of diazepam tested effective in depressing reflex increment was $0.125 \mathrm{mg} / \mathrm{kg}$ $(P>0.02)$ while $0.25 \mathrm{mg} / \mathrm{kg}$ was necessary for the depression of reflex decrement $(P>0.02)$. Panels D, E and F (Fig. 2) depict a rare occurrence with regard to the BI response. Inhibition here is not only completely depressed, but converted to facilitation as well.

Panel A (Fig. 2) illustrates the dual effects of reticular stimulation on the linguomandibular and patellar reflex responses. Stimulation of BF reticular areas produced facilitation of the patellar reflex paired with sustained maximal jaw closure, whereas BI stimulation produced inhibition of the patellar reflex and sustained maximal opening of the mouth.

The jaw closure (downward deflection) response had a longer duration than the period of reticular (BF) stimulation (panel A, Fig. 2). With increasing doses of diazepam this response was progressively diminished. The jaw opening (upward deflection) response remained constant throughout.

The pressor response (panel A, Fig. 2) due to reticular (BF) stimulation was attenuated by increasing doses of diazepam.

Motor cortical EEG amplitude was consistently reduced by doses of diazepam (compare panel A and F, Fig. 2). However, any interpretation of EEG of an anesthetized animal is very much open to question. In this regard such amplitude changes of the EEG were not observed in unanesthetized cats given equal doses of diazepam.

\section{Effects of diazepam on mid-collicular (gamma-driven) decerebrate rigidity}

The rigidity of the mid-collicular decerebrate cat was abolished by small doses $(0.125$ $\mathrm{mg} / \mathrm{kg}$ ) of diazepam). This is illustrated in Fig. 3 by the depression of the electromyogram (EMG) recorded from neck muscles (panels A-E), reduction of general extensor and flexor tone as depicted by the lowering of the patellar reflex (PR) baseline (panel $A$ ) and the increase of the PR amplitude above peak control levels (panel D, E). Diazepam also caused a reduction in response to left pinna stimulation (panels A-E).

Pinna (left) stimulation in the mid-collicular decerebrate cat caused turning of the head to the'contralateral side, flexion of the left fore and right hind limbs and enhanced extension of the right fore and left hind limbs. The increased extension of the left hind limb is depicted as a patellar reflex increment (Fig. 3, panel $\mathrm{A}$ - control) while flexion of the left forelimb is superimposed upon the forelimb tone (FT) trace (Fig. 3, panel A-control) as a reduction in extensor tonus during pinna stimulation. This induced flexion of the left forelimb ceased following the initial dose $(0 \cdot 125 \mathrm{mg} / \mathrm{kg}$ ) of diazepam (Fig. 3, panel A). The turning of the head to the contralateral side was likewise depressed.

Due to decerebration, the left hind limb displayed a maintained exaggerated reflex extensor tone illustrated in Fig. 3 (panel A-control) as a $30 \mathrm{~g}$ elevation of the patellar reflex (PR) baseline. Diazepam $(0.125 \mathrm{mg} / \mathrm{kg})$ causes a reduction of extensor tone (i.e. fall in the PR 


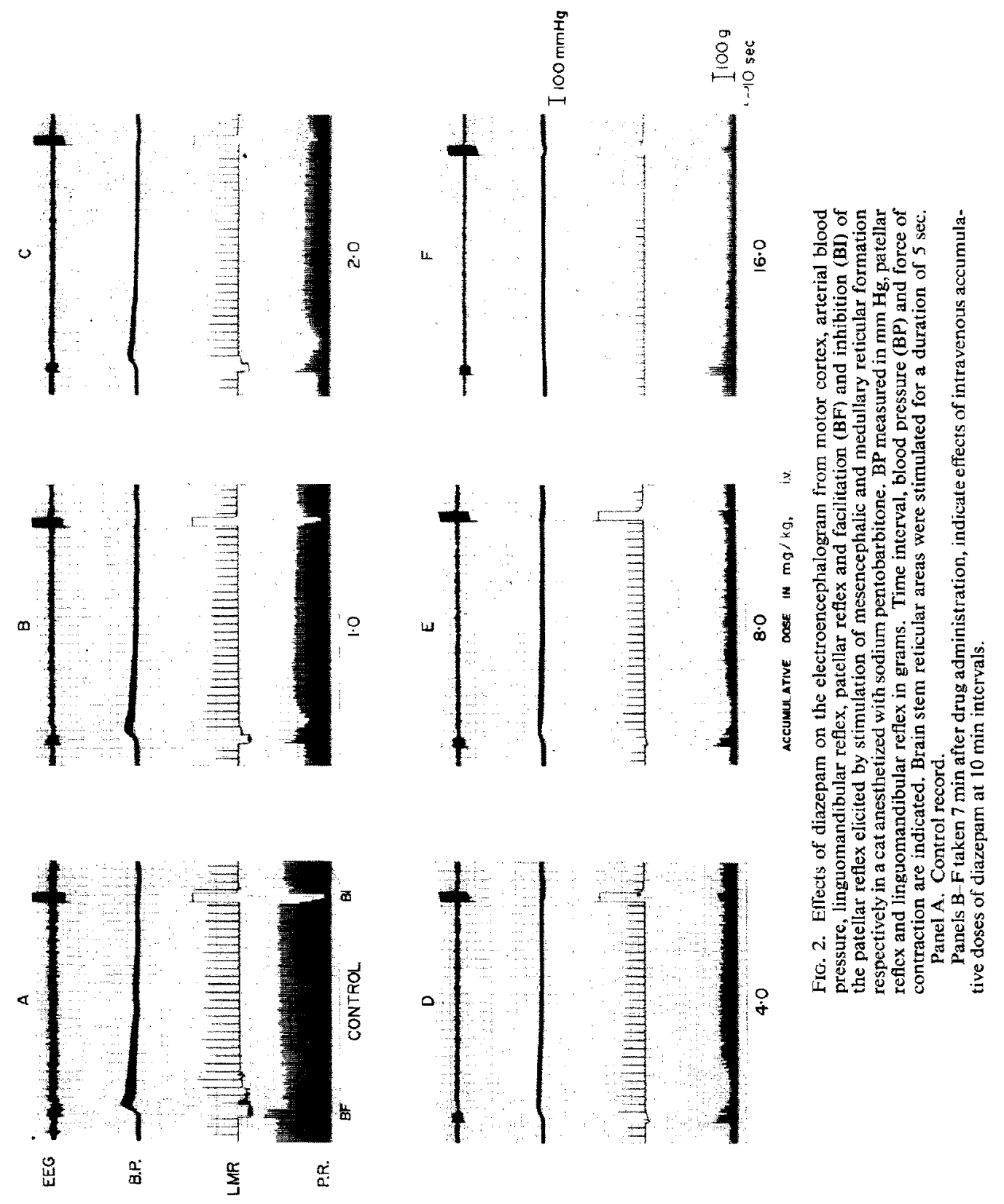


$\mathbf{A}$

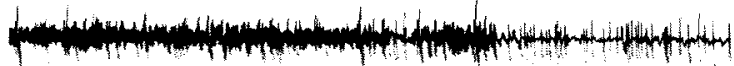

B.P.

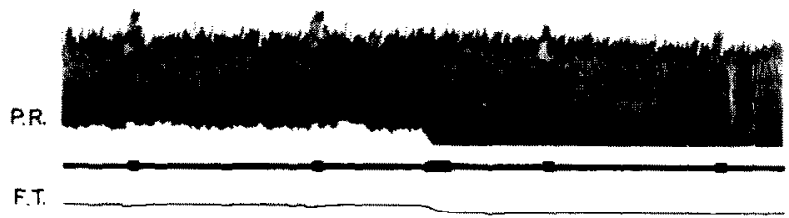

Control

0.25

C

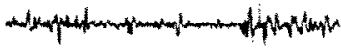

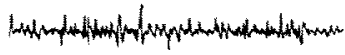
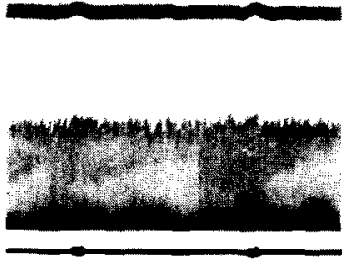

4-0

8. 0
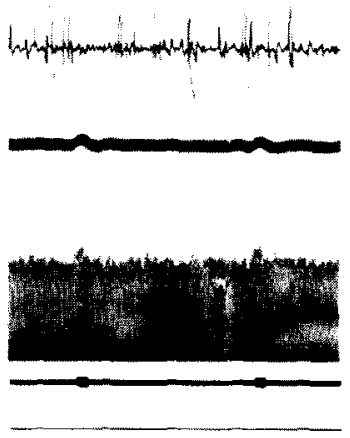

1.0

$E$

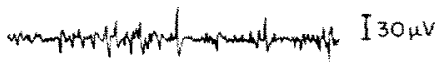
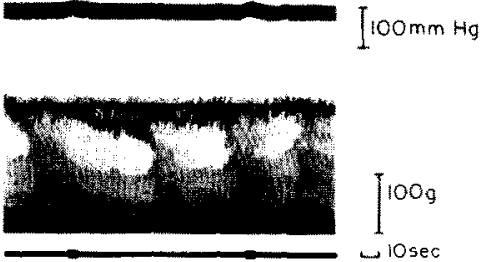

1009 .

16.7

ACCUMULATIVE DOSE IN $\mathrm{mg} / \mathrm{kg}$, iv

FIG. 3. Effects of diazepam on the electromyogram (EMG) of the neck muscles, arteriai blood pressure (BP), patellar reflex (PR) and forelimb tone (FT) of a mid-collicular (gamma-motor driven) decerebrate cat. Forelimb tone is a measure of the force exerted upon a force displacement transducer by the rigidity extended left forelimb. Small markers on the timer line indicate $5 \mathrm{sec}$ periods of stimulation of the ipsilateral pinna producing facilitation of the patellar reflex. The large marker on the timer line of panel $A$ indicates the period of administration of diazepam $(0.125 \mathrm{mg} / \mathrm{kg})$ intravenously. The lowering of PR and FT baselines indicate a reduction of extensor tone in response to diazepam (panel A). The time base, force calibrations of the patellar reffex excursions and forelimb tone in $\mathrm{g}$ and the calibration for the blood pressure in $\mathrm{mm}$ of $\mathrm{Hg}$ are indicated. With the exception of the initial drug dose (panel A) all records were taken 7 min after drug administration. Cat was anesthetized with ether and allowed $3 \mathrm{hr}$ for recovery before experiment was begun. 


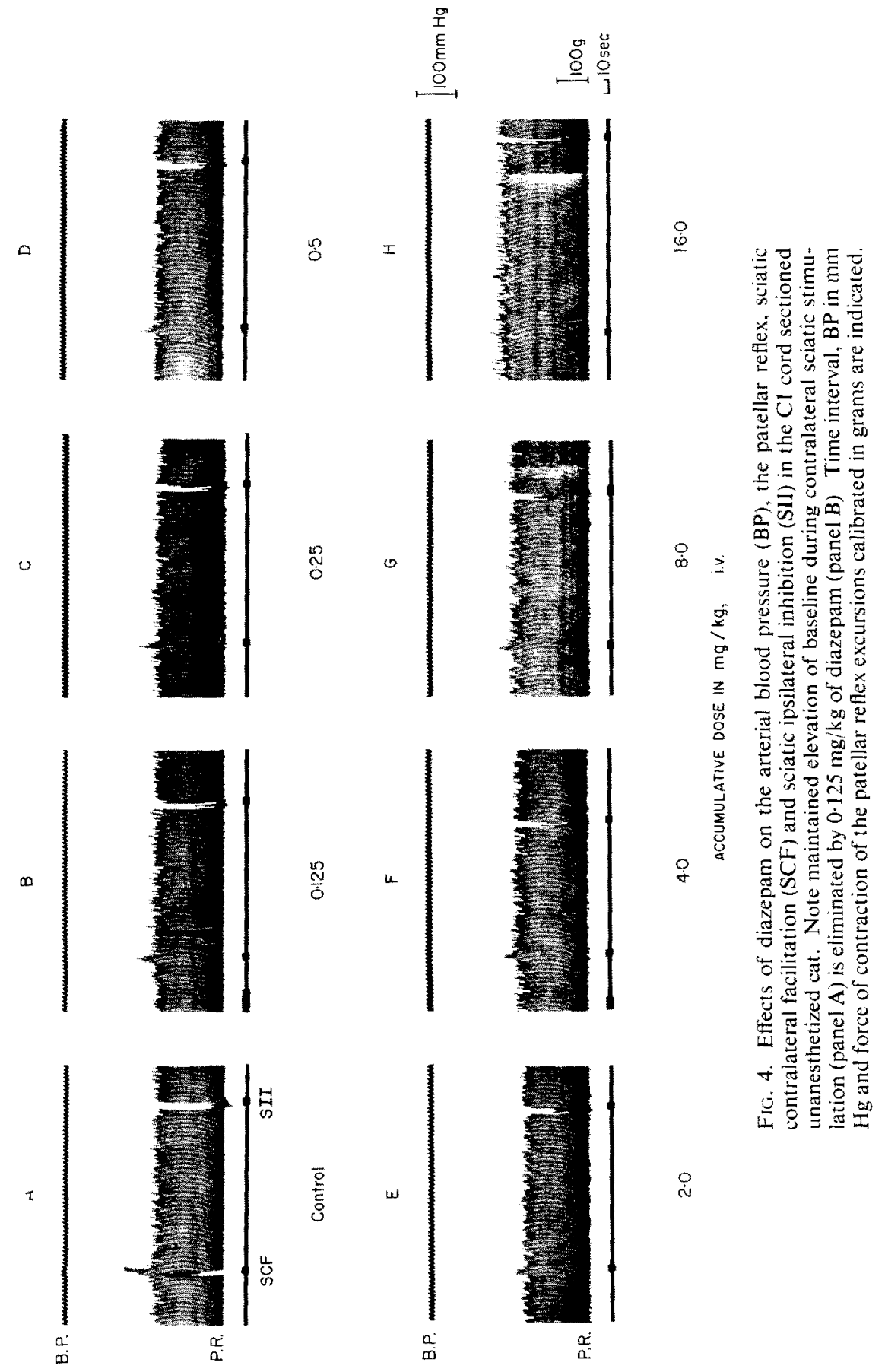


baseline) and by this an increase of the patellar reflex excursion (Fig. 3, panel A). An actual increase of the basal patellar reflex amplitude above peak control values does not occur until the administration of $8-16 \mathrm{mg} / \mathrm{kg}$ of diazepam (Fig. 3, panels D, E). This response to high doses of diazepam makes an interpretation of diazepam's effect on patellar reflex increment at these levels (panels D, E) quite difficult. At smaller drug doses (Fig. 3, panel A-C) a comparison of test reflex increment to control reflex increment shows this response to be depressed $(P<0.02)$.

Mean arterial blood pressure was depressed $(P<0.05)$ by the cumulative dose of $2 \mathrm{mg} / \mathrm{kg}$ of diazepam. In general, blood pressure was more resistant to depression in the decerebrate cat than in the intact cat,

Effects of diazepam on patellar and linguomandibular reflexes and arterial blood pressure in the high spinal cat

The basal patellar refiex amplitude and arterial blood pressure were not depressed by diazepam (Fig. 4), but were frequently increased at large doses $(8-16 \mathrm{mg} / \mathrm{kg})$. The linguomandibular reflex was depressed $(P<0.05)$ by the cumulative dose of $1 \mathrm{mg} / \mathrm{kg}$ of diazepam (Fig. 5).

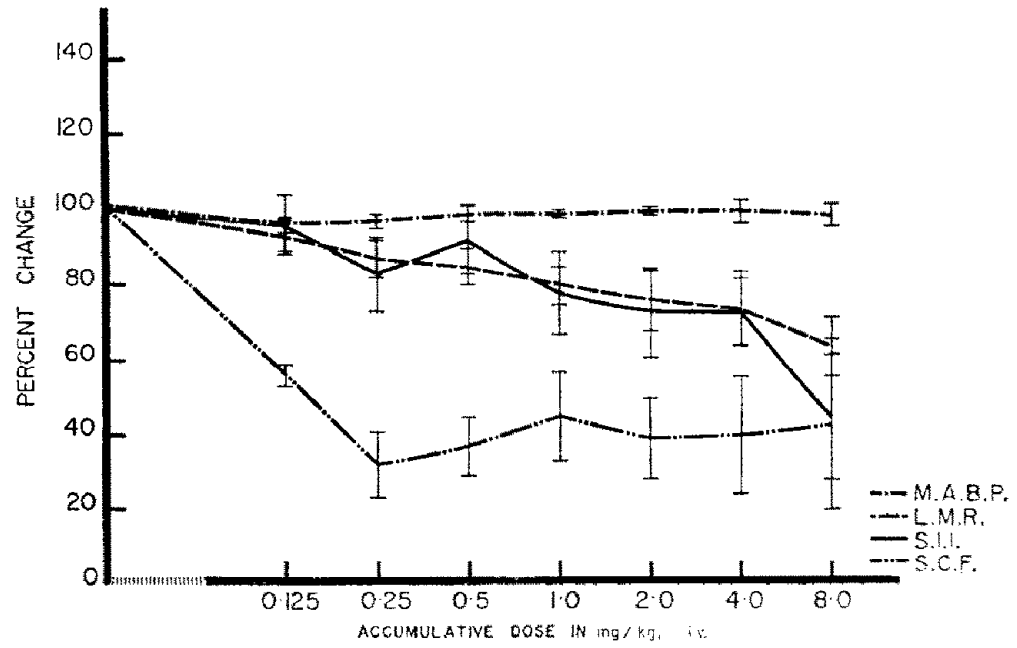

FIG. 5. Effects of diazepam on mean arterial blood pressure (M.A.B.P.), sciatic ipsilateral inhibition (S.I.I.), sciatic contralateral facilitation (S.C.F.) and the linguomandibular reflex (L.M.R.) in high (C1) spinal unanesthetized cats. The data from 10 cats are expressed as in Fig. 1.

Effects of diazepam on spinal cord evoked inhibition and facilitation of the patellar reflex in the high spinal cat

Reflex increment produced by contralateral sciatic nerve (SCF) stimulation was depressed $(P>0.01)$ by small doses $(0.125 \mathrm{mg} / \mathrm{kg}$ ) of diazepam (Figs. 4,5$)$. Sciatic nerve stimulation (SCF) in some cats produced a maintained tonic extension upon which the facilitated patellar reflex excursions were superimposed (Fig. 4, panel A). The initial dose of diazepam $(0 \cdot 125$ $\mathrm{mg} / \mathrm{kg}$ ) abolished this tonic aspect of the facilitatory (SCF) response (Fig. 4, panel B).

Reflex decrement produced by sciatic nerve stimulation (SII) was most resistant to depression (Figs. 4,5$)$ yielding only at high doses $(8-16 \mathrm{mg} / \mathrm{kg}$ ). This sciatic-induced reflex decrement was more resistant to diazepam depression than reflex decrement produced by 
direct stimulation of the cord $(\mathrm{Cl}-2)$ in spinal animals. Reflex increment and decrement produced by stimulation of cervical cord $(\mathrm{Cl}-2)$ were depressed by $1-8 \mathrm{mg} / \mathrm{kg}$ of diazepam $(P<0.02)$.

The above tests were made in groups of cats anesthetized with either alpha-chloralose, sodium pentobarbitone, or diethyl ether (allowed to recover from anesthesia). Reflex increment and decrement were depressed regardless of the anesthetic used.

The intact, alpha-chloralose anesthetized cat was compared to each of these variously anesthetized spinal groups with regard to reflex increment and decrement. This comparison showed reflex decrement in the spinal cat to be more resistant to depression by diazepam $(P<0 \cdot 01)$. Reflex increment appeared to be similarly depressed by diazepam in both the intact and high spinal $(\mathrm{Cl})$ cat.

\section{DISCUSSION}

Diazepam depresses both the patellar (PR) and linguomandibular (LMR) reflexes in intact cats. In cats with a high spinal section $(\mathrm{Cl})$ only the LMR is depressed. These results, combined with the motor depression observed in the mid-collicular decerebrate cat, suggest a brain stem site of action for diazepam, but they do not exclude a spinal site. For example, diazepam might modify, at the spinal level, supraspinal influences on the PR. Experiments involving high spinal section would not reveal such a mechanism.

Some difficulty is encountered in interpreting the effects of large doses $(8-16 \mathrm{mg} / \mathrm{kg})$ of diazepam on reflex increment and decrement in the spinal and decerebrate cal. These doses increased the basal patellar reflex amplitude above peak control values. This increase does not appear to be due to a direct effect on the muscle since no such effect was observed in the neuromuscular preparation. The depressant effects of diazepam on reflex increment and decrement were more discernible at smaller doses $(0 \cdot 125-4 \mathrm{mg} / \mathrm{kg})$ where the basal patellar reflex is neither depressed nor increased above peak control values.

The lack of basal patellar reflex depression in the spinal cat was probably due to the absence of a "diazepam sensitive barrage" of background neural activity of supraspinal origin. The depression of evoked reflex activity in the spinal cat without a reduction of the basal patellar reflex suggests that diazepam, though exerting a depression on spinal neural circuits, has little influence directly upon the elements of the patellar reflex arc.

The importance of the background neurologic milieu with which a drug interacts cannot be overemphasized as is well illustrated in this study. Diazepam apparently produced paradoxical effects on the patellar reflex (PR) amplitude as observed in the intact, spinal and decerebrate cat.

In the intact cat, the PR was reduced $(P<0.02)$, and in the decerebrate cat the amplitude was unchanged or increased. Regardless of superficial appearances, these observations exhibit no contradiction in diazepam's effects. The apparent differences can be reconciled on the basis of the predominant neurological background activity of each preparation used.

In the intact cat there are continuous impulses originating at supraspinal levels which descend to the spinal cord and influence the excitatory tonus of the lower motoneurons and thus skeletal muscle tone (MAGOUN and RHINES, 1947). In these animals diazepam reduces the patellar reflex amplitude by suppressing "normal" mesencephalic reticular discharge to lower motoneurons.

The decerebrate cat presents exaggerated facilitatory impulses of brain stem origin. This is due in part to the loss of counterbalancing inhibitory forces. The imbalance is of such magnitude that the antigravity muscles become rigidly contracted, limiting patellar reflex 
excursions. In such an animal, diazepam acts centrally to suppress the exaggerated supraspinal drive as it does the "normal" supraspinal drive of the intact animals. This central suppression reduces the limiting effects of the peripheral muscle rigidity, resulting in an increase in the patellar reflex excursion.

In the spinal cat the supraspinal driving force of the bulbospinal system upon which diazepam apparently displays its effects is "inactive" at spinal levels. Inactivation of this system by cord section precludes the observation of diazepam's depressant effects on the patellar reflex. However, electrophysiological stimulation of the bulbospinal system in such preparations makes spinal cord responsiveness to the effects of diazepam quite evident.

In postulating the brain stem reticular formation and the spinal cord as sites of action of diazepam on motor function, several other conceivable interpretations for the observed effects have been considered and ruled out.

The lack of depression of the basal patellar reflex in the high spinal cat rules out the likelihood that diazepam depresses afferent and/or efferent nerve conduction, transmission across the neuromuscular junction, the muscle spindle or the contractile elements of skeletal muscle. Experiments in neuromuscular preparations also support the lack of a peripheral depressant effect. Likewise the motor depressant effects of diazepam are not dependent upon the potentiation of anesthesia. This is shown by the depression of the linguomandibular reflex and evoked spinal reflex responses in the unanesthetized spinal transectioned cat.

Clinical observations of OLAFSON et al. (1964) suggest that diazepam may indeed exert some portion of its muscle relaxant action via a spinal mechanism. The investigators observed a distinct similarity between the "stiff-man" syndrome and tetanus toxicity. Both diseases result in muscle tautness and spasm, and in both, the spasms are triggered by external stimuli. Tetanus toxin, like strychnine, is known to exert its effect by blocking recurrent inhibition in the spinal cord (Brooks et al., 1957). Clinical evaluation of several cases of the "stiff-man" syndrome led Or.AFson et al. (1964) to postulate that this condition was produced by a block of the synaptic junction between the Renshaw inhibitory neuron and the alpha motoneuron. The therapeutic effectiveness of diazepam on the rare "stiff-man" syndrome was interpreted as suggesting a spinal site of action for diazepam. Evidence presented in the present study of the action of diazepam on the spinal cord supports this interpretation.

The hypothesis of an impairment of spinal inhibition in the "stiff-man" syndrome (OlaFson et al., 1964) prompted a search for an agent which might act by potentiating spinal inhibitory function. Even though diazepam has not been demonstrated to potentiate postsynaptic inhibition it has been reported to enhance presynaptic inhibition at a spinal cord level (STRATTEN and BARNES, 1968). It has also been suggested that the motor relaxation produced by diazepam may in some way be related to a reduction of gamma efferent discharge (HeRnÁNDEZ-PEÓN et al., 1964). However, it is known that diazepam is effective in depressing skeletal muscle tone in situations of minimal gamma efferent discharge. This is evidenced by the relaxant action of diazepam observed in the anemic decerebrate animal (RANDALL et al., 1961). In this preparation, as opposed to the mid-collicular decerebration, the gamma motoneurons are only minimally active and the rigid condition is maintained primarily by alpha motoneuron discharge (STELLA, 1944a, b). Further study is necessary for the clarification of the mechanismal basis for the muscle relaxant effects of diazepam at both the brain stem and spinal cord levels.

Pressor responses produced by brain stem reticular stimulation in this study were depressed by diazepam. The site of this depression was apparently within the central nervous 
system since pressor responses to injected adrenergic substances (RANDALL et al., 1961) and those due to stimulation of stellate ganglia (SCHALleK and ZABRANSKY, 1966) are not altered by diazepam.

The mean arterial blood pressure was depressed by small doses of diazepam and elevated by large doses. The present study offers no conclusive information as to causative factors involved.

On the basis of evidence presented in this investigation it is suggested that diazepam produces its relaxant effects by a depression of motor systems of both the brain stem reticular formation and the spinal cord.

\section{REFERENCES}

Brooks, V. B., Curtis, D. R. and Eccles, J. C. (1957). The action of tetanus toxin on the inhibition of motoneurons. J. Physiol., Lond. 135: 655-672.

Hernández-Peón, R., Rojas-Ramirez, J. A., O'Flaherty, J. J. and Mazzuchelli-O'Flaherty, A. L. (1964). An experimental study of the anticonvulsive and relaxant actions of valium. Int. J. Neuropharmac. 3: 405-412.

Hudson, R. D. (1966). Effects of chlorpromazine on spinal cord reflex mechanisms. Int. J. Neuropharmac. 5: $43-58$.

Hudson, R. D. and Domino, E. F. (1963). Effects of chlorpromazine on some motor reflexes. Int. J. Neuropharmac. 2: 143-162.

Hudson, R. D. and Wolpert, M. K. (1968). Diazepam on motor systems (two sites of action). Fedn Proc. 27: 571 .

Maroun, H. W. and Ruines, R. (1947). Spasticity. The Stretch Reffex and Extra-pyramidal Systems. p. 59, Thomas, Springfield.

Ngai, S. H., Tseng, D. T. C. and WANG, C. (1966). Effects of diazepam and other central nervous system depressants on spinal reflexes in cats: A study of site of action. J. Pharmac. exp. Ther. 153: 344-351.

Olafson, R. A., Mulder, D. W. and Howakd, F. M. (1964). "Stiff-man" syndrome: A review of the literature, report of three additional cases and discussion of pathophysiology and therpy. Mayo Clinic Proc. 39: $131-144$.

Przybyla, A. C. and WANG, S. C. (1968). Locus of central depressant action of diazepam. J. Pharmac. exp. Ther. 163: 439-447.

Randall, L. O., Heise, G. A., Schallek, W., Bagdon, R. E., Banziger, R., Boris, A., Moe, R. A. and Abrams, W. B. (1961). Pharmacological and clinical studies on Valium a new psychotherapeutic agent of the benzodiazepine class. Curr. ther. Res. 3:405-425.

SCHALLEK, W. and ZABRANSKY, F. (1966). Effects of psychotropic drugs on pressor responses to central and peripheral stimulation in the cat. Archs. Int. Pharmacodyn. 161: 126-131.

SCHALleK, W., ZaBransky, F. and KueHN, A. (1964). Effects of Benzodiazepines on central nervous system of cat. Archs. Int. Pharmacodyn. 149: 467-483.

Stella, G. (1944a). Sul meccanisimo della rigidità da cerebrazione in arti deafferentati. Atti. Soc. med Chir. Padova 22: 5-16.

Stella, G. (1944b). Influenza del cerveletto sulla rigidità da decercbrazione. Atti. Soc. med Chir. Padova 22: $17-21$.

Stratten, W. P. and Barnes, C. D. (1968). Spinal effect of diazepam. Fedn. Proc. 27: 571.

Svenson, S. E. and Gordon, L. E. (1965). Diazepam: A progress report. Curr. ther. Res. 7: 367-391. 